EPJ Web of Conferences 110,01050 (2016)

DOI: $10.1051 /$ epjconf/201611001050

(C) Owned by the authors, published by EDP Sciences, 2016

\title{
REDUCTION OF NITROGEN OXIDES EMISSIONS FROM A COAL-FIRED BOILER UNIT
}

\author{
Andrey V. Zhuikov ${ }^{1,}$ a , Dmitry V. Feoktistov ${ }^{2,3}$, Natalya N. Koshurnikova ${ }^{1}$, Lyudmila V. Zlenko ${ }^{1}$ \\ ${ }^{1}$ Siberian Federal University, 660041 Krasnoyarsk, Russia \\ ${ }^{2}$ National Research Tomsk Polytechnic University, 634050 Tomsk, Russia \\ 3 S.S. Kutateladze Institute of Thermal Physics, Siberian Branch, Russian Academy of Sciences, 630090, \\ Novosibirsk, Russia
}

\begin{abstract}
During combustion of fossil fuels a large amount of harmful substances are discharged into the atmospheres of cities by industrial heating boiler houses. The most harmful substances among them are nitrogen oxides. The paper presents one of the most effective technological solutions for suppressing nitrogen oxides; it is arrangement of circulation process with additional mounting of the nozzle directed into the bottom of the ash hopper. When brown high-moisture coals are burnt in the medium power boilers, generally fuel nitrogen oxides are produced. It is possible to reduce their production by two ways: lowering the temperature in the core of the torch or decreasing the excess-air factor in the boiler furnace. Proposed solution includes the arrangement of burning process with additional nozzle installed in the lower part of the ash hopper. Air supply from these nozzles creates vortex involving large unburned fuel particles in multiple circulations. Thereby time of their staying in the combustion zone is prolonging. The findings describe the results of the proposed solution; and recommendations for the use of this technological method are given for other boilers.
\end{abstract}

\section{Introduction}

Coal-fired steam and hot water boilers are the most common variants for heat sources of social and industrial facilities. The main problem of using such equipment is nitrogen oxides emissions to the atmosphere generated during coal combustion [1].

Technologies of solid fuel staged combustion with air portion supply above the main burners are known to allow reducing the concentration of nitrogen oxides by 40-50\% [2-8]. But implementing these technologies the gas temperature at the outlet of the furnace increases. And it is not acceptable for boilers burning brown high-moisture coal, because it increases the contamination of the heating surfaces.

The purpose of this work is to investigate the possibility to arrange the combustion process focused on reducing nitrogen oxide emissions without reduction of boiler efficiency.

When coal is fired, the vortex flow is being formed in the furnace due to the interaction between the burner jet and air directed to clean the main burners from the deposited coal-dust. This air is supplied after the air heater through two nozzles. The first of them is directed into the bottom of the

\section{a Corresponding author: a.v.zhuikov@mail.ru}


ash hopper, the second one is located on the opposite side of the main burners (Fig. 1). It allows to arrange staged combustion and to reduce the content of nitrogen oxides in flue gases.

\section{Experimental part}

The arrangement of circulation process due to mounting of the nozzle directed into the bottom of the ash hopper is proposed [9]. This nozzle is made of two parallel channels connected to each other and directed parallel to the frontal slope of the ash hopper at an angle of $57^{\circ}$ (Fig. 1). Due to the aerodynamic interaction of torches (burner and flat from the undergrate air blast) bushy flame is formed. Arising circulation creates the conditions for burning out of large particles due to increasing the time of their staying in the combustion chamber at multiple returns to the place of fresh oxidant supply.

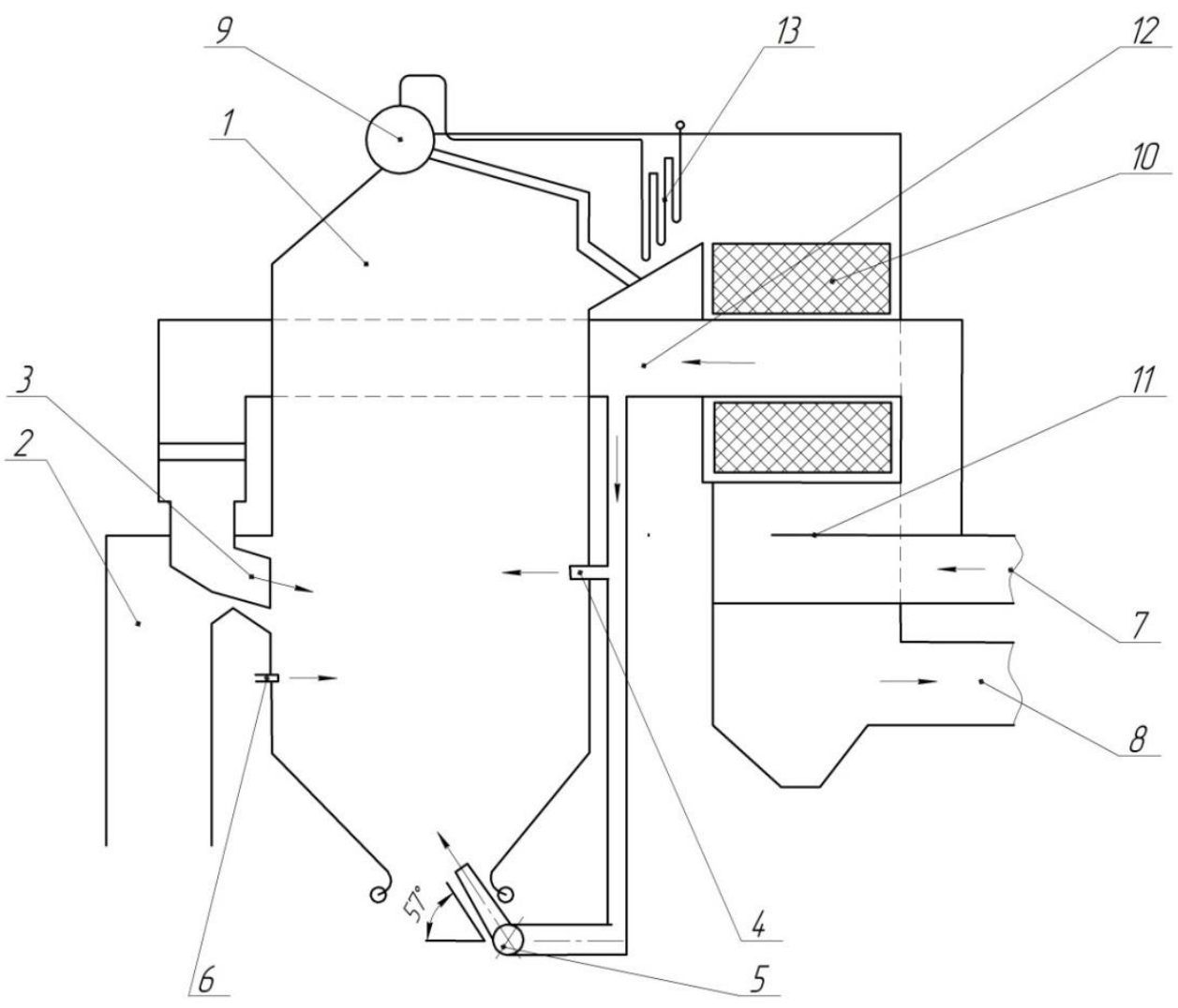

Figure 1. Schematic of burning process arrangement with additional mounting of the nozzle directed into the bottom of the ash hopper. 1 - boiler furnace; 2 - coal-pulverization system; 3 - nozzle for oxidizer feeding; 4 nozzle located on the opposite side of the main burners; 5 - nozzle directed into the bottom of the ash hopper; 6 nozzle for cleaning the main burners from the deposited coal-dust; 7 - input air to the air heater; 8 - flue gases; 9 - drum boiler; 10 - feed-water economizer; 11 - air heater; 12 - output air from the air heater; 13 - superheater.

Thus, the ash hopper (the lower part of the furnace) is involved in the heat exchange process; and it reduces the flue gases temperature at the furnace outlet. Contamination of the convective heating surfaces is reduced by increasing the length of the combustion process in the entire volume of the combustion chamber with a fresh oxidant supply along the length of the torch.

The flue gases temperature decrease was obtained due to two factors. Firstly, it is the creation of turbulent fluctuations with great depth of the mixing zone in the furnace volume by the interaction of 
the fuel-air mixture jet and secondary blast air directed at an angle to the symmetry axis of the torch. The latter contributes to the formation of circulating flows.

Secondly, the initial region of the torch is cooled by streams from the furnace hopper. There is the effect of the thermal emission and hydrodynamic instability. Small-sized steady turbulent vortexes are formed. And fuel particles circulate multiply in the combustion chamber volume due to these vortexes.

Experimental investigations of the burning process arrangement were conducted on the brown coal fired boiler unit. Analysis of flue gases for $\mathrm{O}_{2}, \mathrm{CO}$, and $\mathrm{NO}_{\mathrm{x}}$ concentration and recording of the temperature of flue gases and air are carried out using a portable automatic gas analyzer DAG-510. The instrument error was $3 \%$.

\section{Results and discussion}

Figure 2 shows the dependencies of the nitrogen oxides concentration in flue gases from the boiler load at arrangement of the circulation process of oxidizer feeding to the furnace according to factory settings and with additional mounting of the nozzle directed into the bottom of the ash hopper.

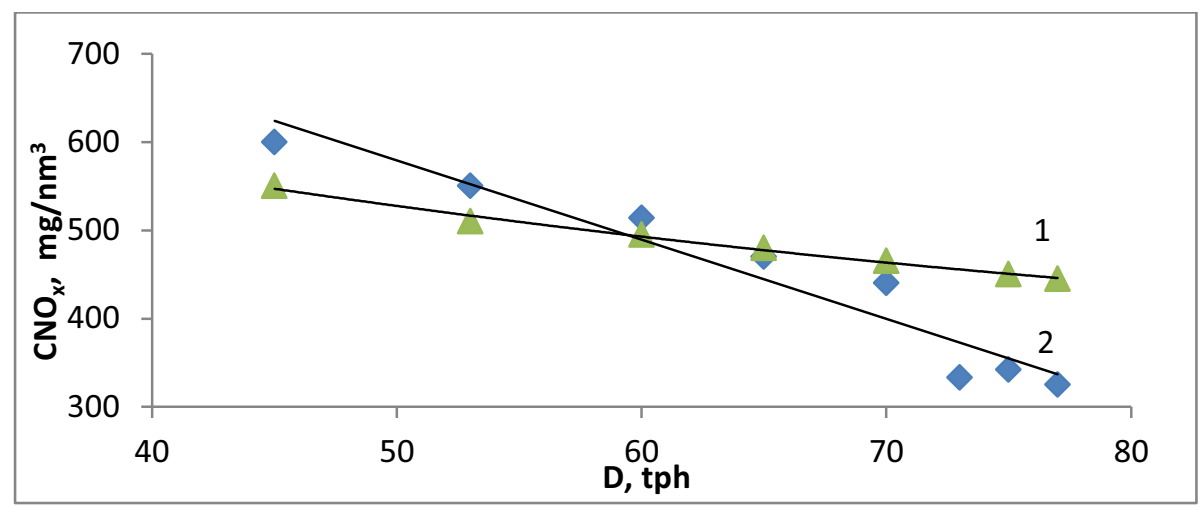

Figure 2. The concentration of nitrogen oxides in flue gases versus the boiler load at arrangement of the circulation process of oxidizer feeding: 1 - according to factory settings, 2 - with additional mounting of the nozzle directed into the bottom of the ash hopper.

Results of the boiler efficiency tests are given in Table 1.

Table 1. Results of the boiler efficiency tests.

\begin{tabular}{|c|c|c|c|c|c|c|}
\hline $\begin{array}{c}\text { Arrangement of } \\
\text { the circulation } \\
\text { process of } \\
\text { oxidizer feeding }\end{array}$ & $\begin{array}{c}\text { Boiler load, } \\
\text { tph }\end{array}$ & $\begin{array}{c}\text { Excess-air factor } \\
\text { after the boiler }\end{array}$ & $\begin{array}{c}\mathrm{NO}_{\mathrm{x}} \\
\text { concentration, } \\
\mathrm{mg} / \mathrm{nm}^{3}\end{array}$ & $\begin{array}{c}\text { Unburned } \\
\text { carbon } \\
\text { loss } q_{4}, \%\end{array}$ & $\begin{array}{c}\text { Flue gas } \\
\text { loss } q_{2}, \\
\%\end{array}$ & $\begin{array}{c}\text { Gross } \\
\text { efficiency } \\
\text { of boiler }\end{array}$ \\
\hline Factory settings & 75 & 1.35 & 450 & 0.34 & 8.6 & 90.1 \\
\hline $\begin{array}{c}\text { With additional } \\
\text { mounting of the } \\
\text { nozzle }\end{array}$ & 75 & 1.3 & 340 & 0.3 & 7.54 & 91.2 \\
\hline
\end{tabular}

According to results of the boiler efficiency tests it has been found that the implementation of proposed arrangement of the burning process with additional mounting of the nozzle directed into the bottom of the ash hopper decreased the concentration of nitrogen oxides by $25 \%$ (Table 1 ). This can be explained by the formation of combustion zones in the furnace chamber characterized by the excess of air and temperature. In other words, only one combustion zone was in the furnace before 
reconstruction; and after reconstruction two zones are formed. The bulk of fuel $(65-75 \%)$ is burnt in the first combustion zone at a slight excess of air. The rest of fuel is burnt in the second zone (zone of the furnace hopper) at using air from the additional nozzle.

\section{Conclusions}

Implementation of the circulation process arrangement allows to reduce the emissions of nitrogen oxides by $110 \mathrm{mg} / \mathrm{m}^{3}$; unburned carbon loss decreases by $0.04 \%$. Lowering the temperature of the torch by $50-100{ }^{\circ} \mathrm{C}$ caused the decrease of the flue gas temperature, which contributed to the reduction of loss $\mathrm{q}_{2}$ by $1.06 \%$. The gross efficiency of boiler has increased by $1.1 \%$.

Increase of the heating surface contamination was not observed after mounting of the additional nozzle directed into the bottom of the ash hopper.

The developed scheme of the circulation process arrangement with the additional nozzle can be used for dry-bottom medium power boilers working on highly reactive brown coals.

\section{Acknowledgement}

The work was realized within the research state assignment "Science" №13.1339.2014/K (Code of Federal Target Scientific and Technical Program 2.1410.2014).

\section{References}

1. N. Cariln, K. Annamalai, W. Harman, J. Sweeten, Biomass Bioenergy 33, 1139 (2009)

2. P. Edge, P. Heggs, M. Pourkashanian, P. Stephenson, Appl.Therm. Eng. 60, 242 (2013)

3. S. Belosevic, I. Tomanovic, V. Beljanski, D. Tucakovic, T. Zivanovic, Appl. Therm. Eng. 74, 102 (2015)

4. W. Adamczyk, P. Kozolub, G. Wecel, A. Ryfa, Int. J. Numer. Methods Heat. Fluid Flow 24, 845 (2014)

5. L. Chen, S. Zheng, A. Ghoniem, Prog. Energy Combust. Sci. 38, 156 (2012)

6. S. Werle, Impact of the feedstock properties and the operating conditions on the sewage sludge gasification process in the fixed bed gasifier (Proceedings of 26th International Conference ECOS, Guilin, China, 2013)

7. G. Stupar, D. Tucakovic, T. Zivanovic, S. Belosevic, Appl. Therm. Eng. 78, 397 (2015)

8. R. Corrêa da Silva, H.J. Krautz, Appl. Therm. Eng. 64, 430 (2014)

9. Useful model patent № 116203 Russian Federation, IPC ${ }^{7}$ F23C 5/00 2011149438/06; Lowemission swirling - type furnace, A.V. Zhuikov, appl. from 05.12.11; published 20.05.2012, Report № 14 